\title{
Approach to the patient with advanced differentiated thyroid cancer
}

\author{
M Schlumberger and S I Sherman ${ }^{1}$ \\ Department of Nuclear Medicine and Endocrine Oncology, Centre de Référence 'Tumeurs Réfractaires de la Thyroïde', Institut Gustave Roussy and \\ University Paris-Sud XI, 94800 Villejuif, France and ${ }^{1}$ Department of Endocrine Neoplasia and Hormonal Disorders, University of Texas MD Anderson \\ Cancer Center, Houston, Texas 77030, USA \\ (Correspondence should be addressed to M Schlumberger; Email: schlumbg@igr.fr)
}

\begin{abstract}
Patients with advanced thyroid cancer may benefit from L-thyroxine treatment at doses that suppress serum TSH level, local treatment interventions, and radioiodine therapy. In those patients who are refractory to radioiodine therapy and in whom progressive disease has been documented, the efficacy of cytotoxic chemotherapy is poor. Encouraging results have been obtained with the use of kinase inhibitors that should be offered as first-line treatment, preferably in the context of a prospective trial.

European Journal of Endocrinology 166 5-11
\end{abstract}

\section{Introduction and background}

Differentiated thyroid cancer (DTC) accounts for more than $90 \%$ of all thyroid cancers and includes the papillary, follicular, and poorly differentiated histologic types. In patients with clinical cancer, initial treatment includes a total thyroidectomy and a lymph node dissection in those with known or at high risk of lymph node metastases. Radioiodine treatment is undertaken post-operatively in patients with a significant risk of recurrence or disease-related mortality (1). Then, annual follow-up is performed on thyroxine $\left(\mathrm{T}_{4}\right)$ treatment and is based on neck ultrasonography and serum thyroglobulin $(\mathrm{Tg})$ determination. The use of recombinant human TSH stimulation may permit the early detection of persistent or recurrent disease (1).

Recurrent disease occurs in $10-15 \%$, mostly in patients with extensive disease (large thyroid tumors, extension beyond the thyroid capsule, and lymph node metastases) and in those with an aggressive histologic type (1-4). In three-fourths of cases, recurrent disease is located in the neck only, in lymph nodes, or in the thyroid bed. In patients with persistent or recurrent disease, $\mathrm{L}^{-\mathrm{T}_{4}}$ is given at doses that suppress TSH because increased serum TSH level may enhance tumor growth $(5,6)$. Treatment of neck recurrence includes surgery, radioiodine, and in some patients external radiation therapy (7). Complete remission is achieved in more than two-thirds of patients with recurrent disease in lymph nodes, but recurrences in the thyroid bed are often associated with a poorer prognosis.

Distant metastases are observed in fewer than $10 \%$ of DTC patients, with half of them being detected at presentation. They are located in the lungs $(50 \%)$, bones $(25 \%)$, lungs and bones $(20 \%)$, or at other sites (5\%) (4). Treatment of distant metastases includes $\mathrm{L}-\mathrm{T}_{4}$ treatment at doses that suppress $\mathrm{TSH}$, local treatment modalities (such as surgery, radiation therapy, and radiofrequency ablation), and radioiodine in two-thirds of patients who demonstrate significant radioiodine uptake in their metastases. These methods provide a complete remission in only one-third of patients with distant metastases (4). The other patients have radioiodine refractory disease (defined as having at least one lesion without radioiodine uptake or that has progressed within a year following radioiodine treatment or with persistent disease after the administration of a cumulative activity of more than $22 \mathrm{GBq}(600 \mathrm{mCi})$ radioiodine). The median survival after the discovery of distant metastases in patients with refractory DTC ranges from 3 to 6 years (4), but slow tumor growth is common, particularly in young patients with well-differentiated tumors.

\section{Search strategies}

All papers written in English found on PubMed between 2000 and 2010 using the key words 'metastatic thyroid cancer, radioiodine, targeted therapies' were analyzed. 


\section{Selection of patients for clinical trials}

Patients with radioiodine refractory metastatic DTC must be accurately characterized concerning all clinical prognostic indicators, including age, performance status, histology, disease extent and location, and progression rate.

Once DTC is found to be refractory to radioiodine, diagnostic procedures should include neck ultrasonography; contrast-enhanced spiral computed tomography (CT) scan of the neck, chest and abdomen; and a CT scan or magnetic resonance imaging (MRI) of the brain. As slowly growing bone metastases are often difficult to visualize on bone scintigraphy, MRI of the spine and pelvis should be considered. A baseline fluorine-18 fluorodeoxyglucose positron emission tomography $\left({ }^{18}\right.$ FDG PET) scan may complete the work-up to aid disease localization, prognostication, and response to treatment $(1,3)$. It may also point out neoplastic foci with higher FDG uptake that may require local treatment interventions.

Imaging should emphasize identification of all clinically relevant sites of disease, including those tumors that are large enough to be serially assessed to determine progression and response to therapy, as well as those that might require additional localized intervention, such as surgery, external radiation therapy, radiofrequency ablation, cryotherapy, cement injection, or embolization. These treatment modalities may permit to postpone the initiation of a systemic treatment.

Progression rate is assessed with standardized imaging that is repeated every 6 months, using response evaluation criteria in solid tumors (RECIST) $(8,9)$. There is no evidence that efficacy of the novel treatment modalities is better at an early stage than at a later stage when metastases are larger in size, and in most patients, initiation of a systemic treatment can be postponed until disease progression has been documented. Many patients with metastatic DTC can be asymptomatically stable for long periods of time, and in such patients, the benefits of novel therapies may be largely outweighed by drug toxicities and rigors of clinical trial participation $(2,3)$. Patients with measurable lesions and documented progression in a given time interval (between 6 and 15 months) should be considered candidates for systemic treatment. Progression rate, that can also be evaluated by the doubling time of serum $\mathrm{Tg}$, should always be confirmed by imaging $(8,9)$.

\section{Standard systemic treatments}

Cytotoxic chemotherapies provided low response rates in patients with advanced and progressive refractory thyroid cancer and toxicity was high. The more frequently tested agent in thyroid cancer patients is doxorubicin, used either alone or in combination with cisplatin. Tumor response rates range from 0 to $22 \%$, with all responses being partial and only lasting a few months (10-12). Newer cytotoxic drugs, such as taxanes, gemcitabine, or irinotecan, have not been reported in significant number of DTC patients.

\section{Molecular targeted therapies}

Several molecular abnormalities have been defined in DTC and represent potential targets for therapy $(13,14)$.

Molecular targets In $80 \%$ of papillary thyroid cancers, activating mutations have been found in genes encoding signaling molecules of the MAPK pathway and are believed to be the initiating event. This includes rearrangements of RET (denoted RET/PTC) and point mutations of RAS and BRAF, with no overlap between these mutations in primary tumors, with an incidence reported in Table 1. RET/PTC rearrangements are found more frequently in the classical form, RAS mutations in the follicular variant, and $B R A F$ mutations in the tall cell variant (Table 1). In follicular cancers, RAS mutations and $P P A R G-P A X 8$ rearrangements are the main genetic abnormalities; RET/PTC and BRAF mutations have not been found. In poorly differentiated cancers, NRAS mutation is found in $25 \%$ of cases $(15,16)$. The PI3K pathway may also be activated in few papillary and follicular cancers $(17,18)$, and acquisition of additional mutations and gene amplifications that activate this pathway may be a common event in poorly DTCs $(19,20)$. Other molecular abnormalities found in these poorly differentiated tumors, which are believed to be secondary events, include TP53 mutations and overexpression of receptors for

Table 1 Genetic abnormalities observed in thyroid cancers of follicular origin.

\begin{tabular}{lllll}
\hline Genetic alteration & Function & PTC & FTC & PDTC \\
\hline RET mutation & Tyrosine kinase receptor & - & - & - \\
RET rearrangement & Tyrosine kinase receptor & $13-43 \%$ & - & - \\
BRAF mutation & Serine threonine kinase & $45 \%$ & - & $5 \%$ \\
RAS mutation & Small GTPase & $0-21 \%$ & $45 \%$ & $25 \%$ \\
PIK3CA amplification/mutation & Kinase & $3-12 \%$ & $6-28 \%$ & $30 \%$ \\
PAX8/PPARG & & - & $35 \%$ & - \\
TP53 mutation & & - & - & $35 \%$ \\
\hline
\end{tabular}

PTC, papillary; FTC, follicular; PDTC, poorly differentiated thyroid cancer. 
Table 2 Kinase inhibitor activities relevant to thyroid carcinomas.

\begin{tabular}{|c|c|c|c|c|c|c|}
\hline \multirow[b]{2}{*}{ Drug } & \multicolumn{6}{|c|}{$\mathbf{I C}_{50}(\mathrm{~nm})$} \\
\hline & VEGFR1 & VEGFR2 & VEGFR3 & RET & BRAF & Other targets \\
\hline Axitinib & 1.2 & 0.25 & 0.29 & & & \\
\hline Sunitinib & 2 & 9 & 17 & 41 & & \\
\hline Motesanib & 2 & 3 & 6 & 59 & & PDGFR, CKIT \\
\hline Sorafenib & & 90 & 20 & 49 & 6 & \\
\hline Vandetanib & & 40 & 110 & 100 & & EGFR \\
\hline Pazopanib & 10 & 30 & 47 & & & PDGFR, C-KIT \\
\hline Lenvatinib (E7080) & 22 & 4 & 5 & 35 & & PDGFR FGFR-1: 25 \\
\hline
\end{tabular}

epidermal growth factor (EGF) and hepatocyte growth factor (c-Met). These data have been obtained in primary thyroid tumors, and studies in metastatic tissues are still lacking.

Angiogenesis represents another set of potential molecular targets for therapy. Various vascular endothelial growth factors (VEGF) and VEGF receptors (VEGFR-1 (FLT1) and VEGFR-2 (KDR)) as well as receptors for the fibroblast growth factor (FGF) and for the platelet-derived growth factor (PDGF) are often overexpressed in the vascular endothelium of thyroid cancer tissues and they also trigger the MAP kinase signaling pathway $(21,22)$. In experimental models, anti-VEGF therapy blocks the growth of DTC (23).

Molecular targeted therapies used in thyroid cancer Lenvatinib (E7080), motesanib, sorafenib, sunitinib, and vandetanib are multi-kinase inhibitors that share the ability of inhibiting Ret and VEGFR, along with other kinases, and have been used in DTC with the aim of inhibiting the MAPK pathway and angiogenesis. In contrast, axitinib and pazopanib seem to act only as anti-angiogenic agents. An effort has been made to match molecular pathophysiology to drug mechanism of action, and because BRAF mutation is frequently found in papillary thyroid cancers, sorafenib and PLX4032 have been used in these patients (Table 2).

\section{Results of clinical trials}

Available results in DTC patients from phase I and II trials with axitinib, lenvatinib, motesanib, pazopanib, sorafenib, sunitinib, and vandetanib have clearly confirmed the clinical benefits of these compounds. No compound has yet achieved FDA or EMA regulatory approval for therapy of advanced and progressive DTC, but some treatment guidelines recommend the use of available agents for selected patients with progressive metastatic disease based on these phase II results $(1,24)$ (Table 3).

Motesanib The first large, international trial of a tyrosine kinase inhibitor for progressive DTC was a phase II study of motesanib (125 mg/day) on 93 patients: 13 (14\%) achieved a confirmed partial response and another $35 \%$ had a stabilization for more than 24 weeks. Median duration of response was 32 weeks and median progression-free survival (PFS) was 40 weeks (25).

Sorafenib Sorafenib (400 mg twice daily) treatment in DTC was reported in four phase II trials. One trial included 30 patients, of whom seven had a partial response and another 16 had stable disease (26). In another trial in 41 PTC patients, six had a partial response and another 23 had stable disease more than 24 weeks; no partial response was observed among the other 11 patients with FTC or PDTC (27). In a third trial

Table 3 Results obtained in patients with differentiated thyroid carcinoma with kinase inhibitors.

\begin{tabular}{|c|c|c|c|c|c|c|c|}
\hline Study & Drug & Patients $(n)$ & PR (\%) & $\begin{array}{c}\text { SD }>6 \\
\text { months }(\%)\end{array}$ & $\begin{array}{l}\text { Median PFS } \\
\text { (months) }\end{array}$ & $\begin{array}{l}\text { Median OS } \\
\text { (months) }\end{array}$ & $\begin{array}{l}\text { Dose reduction } \\
\text { for toxicity }(\%)\end{array}$ \\
\hline (31) & Vandetanib & 145 & $<5$ & & 11 (van) vs $5.8(\mathrm{pl})$ & $>27$ & 12 \\
\hline (26) & Sorafenib & 30 & 23 & 53 & 20 & $\mathrm{NE}$ & 47 \\
\hline (27) & Sorafenib & 41 PTC & 15 & 56 & 15 & 23 & 52 \\
\hline (28) & Sorafenib & 32 & 25 & 34 & 13.5 & NE & 66 \\
\hline$(29)^{*}$ & Sorafenib & 19 & 18 & 82 & $>24$ & NE & 79 \\
\hline (25) & Motesanib & 93 & 14 & 35 & 9 & $\mathrm{NE}$ & \\
\hline (34) & Axitinib & 45 & 31 & 46 & 18.1 & $>36$ & 38 \\
\hline (33) & Sunitinib & 31 & 13 & 68 & 12.8 & $>24$ & 60 \\
\hline (32) & Sunitinib & 28 & 29 & 50 & & & \\
\hline (35) & Pazopanib & 37 (15 РTC) & $49(33)$ & & 11.7 & $>24$ & 43 \\
\hline (37) & Lenvatinib & $58(43)$ & 45 & 46 & 13.3 & & 39 \\
\hline
\end{tabular}

*Phase III is ongoing. PR, partial response; SD, stable disease; PFS, progression-free survival; OS, overall survival; van, vandetanib; pl, placebo. 
involving 32 patients, eight had a partial response and another 11 had stable disease more than 24 weeks (28). In the fourth trial involving 19 patients, three had a partial response (29). Efficacy of sorafenib was better in papillary cancer than in poorly differentiated cancer, on lung than on bone metastases, and among PTC patients in those with a BRAF mutation. No effect on ${ }^{131}$ I uptake was observed in one study (28). Sorafenib proved to be active also in children with papillary thyroid cancer (30). An ongoing phase III trial is comparing the effect of sorafenib vs placebo on PFS in treatment of naïve patients with radioiodine-refractory, progressive metastatic DTC (NCT00984282).

Vandetanib A randomized phase II trial comparing PFS in refractory DTC treated either with vandetanib (300 mg/day) or with placebo has been completed in 145 patients (31). PFS was significantly improved from 5.8 months in the placebo arm to 11 months in the treatment arm (hazard ratio $=0.63(95 \%$ confidence interval 0.43-0.92)). Unexpectedly, the objective tumor response rate was $<5 \%$ in the treatment group.

Sunitinib In a phase II trial, sunitinib (37.5 mg daily) in 28 DTC patients with FDG-avid disease on PET scans induced a complete response in one patient, a partial response in seven patients, and stable disease in another 14 patients (32). The decrease in FDG uptake at 7 days of sunitinib therapy was greater in patients who had a RECIST response or a stable disease than in those who progressed. In a second phase II trial with 31 evaluable DTC patients with progressive metastases, sunitinib (50 mg/day 4 weeks on-2 weeks off) therapy led to partial responses in 13\% and stable disease in 68\% (33).

Axitinib In a phase II study, axitinib (5 mg twice daily) in 45 DTC patients induced a partial response in 14 and a stable disease for more than 16 weeks in another 19 patients (34). Another phase II trial is still ongoing (NCT00389441).

Pazopanib In a phase II trial, pazopanib (800 mg daily) induced a partial response in $49 \%$ of 37 patients. The likelihood of response lasting longer than 1 year was calculated to be $66 \%$ and PFS at 1 year was $47 \%$ (35). Interestingly, partial responses were more frequently observed in patients with follicular and Hurthle cell cancers than in those with papillary cancers. Maximum concentration of pazopanib in plasma during cycle 1 was significantly correlated with radiographic response ( $r=-0.40, P=0.021$ ), but $43 \%$ of patients required dose reductions owing to adverse events.

Lenvatinib (E7080) E7080 showed promising results in thyroid cancer patients in a phase I trial (36). In a phase II trial, lenvatinib $(24 \mathrm{mg})$ induced a partial response in $45 \%$ of 58 patients (in $53 \%$ of naïve patients and in $42 \%$ of pre-treated patients) and a stable disease in another $46 \%$ of patients. Median PFS was 13.3 months. Dose was reduced in $39 \%$ of patients and the drug was withdrawn in $29 \%$ (37). Based on these results, a phase III trial comparing the effect of lenvatinib vs placebo on PFS in treatment of patients with progressive refractory DTC will be initiated soon.

\section{Selective BRAF and MAPK inhibitors}

RO5185426 (RG7204, PLX 4032) is a selective inhibitor of the V600E mutant BRAF kinase commonly found in PTC. In a phase I trial of RO5185426, among the three patients with PTC who were included, one experienced a partial response and two had disease stabilization (38). XL 281, which inhibits both wild-type and mutant BRAF kinases, is currently in phase I trial (39). Preliminary data described stable disease in five PTC patients (including two patients whose tumors contained BRAF mutations). An additional two patients with Hurthle cell cancer were also treated with prolonged stable disease, but one patient with anaplastic cancer progressed despite treatment.

Selumetinib (AZD6244), an inhibitor of MEK1/2, has been studied in a phase II trial involving 39 DTC patients, treated with $100 \mathrm{mg}$ twice daily (40). There was one partial response and 21 patients with stable disease, with a median PFS of 32 weeks. An ongoing study focuses on whether selumetinib can re-induce radioiodine sensitivity in previous refractory disease (NCT00970359) (41).

\section{Toxicities of molecularly targeted therapies}

Adverse effects from these targeted therapies are significant, including fatigue, hypertension, anorexia, diarrhea, cytopenias, and skin toxicities. These short- or median-term side effects may lead to dose reduction in $11-73 \%$ of patients and to withdrawal of drug in $7-25 \%$. Serum TSH levels should be regularly monitored as they may increase during treatment with any of these kinase inhibitors and this should lead to increase the daily $\mathrm{L}_{-} \mathrm{T}_{4}$ treatment dose (42). Given that these treatment modalities may be given for months or even years, further work is needed to minimize toxicities.

The use of BRAF inhibitors (sorafenib, RO5185426) has been associated with the development of cutaneous squamous cell cancers and keratoacanthomas in up to $21 \%$ of treated patients $(38,43)$. Paradoxical mitogenic stimulation in cells lacking mutant BRAF has been hypothesized to contribute to development of these neoplasms and may also underlie the development of drug resistance in mutant tumors (44).

\section{Conclusion and perspectives}

The majority of patients with DTC can be cured with standard primary treatments; others may survive for 
decades despite persistent disease, and few patients may require novel therapeutic modalities when the disease burden is large and when progression has been documented. These rare thyroid cancer patients should preferably be included in prospective trials, and even phase I trials that are testing the newest therapies should be considered for patients with progressive thyroid cancer, as these protocols may allow early identification of possibly effective drugs (45). Although response criteria in these contemporary trials differ markedly from those evaluating cytotoxic chemotherapy, anti-tumor efficacy of these agents in DTC patients is likely to be much greater than that of earlier chemotherapies. The improvement of PFS that is better related to an improvement of overall survival than response rate was observed in only one study (a randomized phase II trial, vandetanib vs placebo) and needs to be confirmed by phase III trials. Higher response rates have been reported in recent phase II trials with pazopanib and lenvatinib. Whether any one drug has greater efficacy in distinct histologic subtypes remains to be determined.

Drugs used up to now are all anti-angiogenic and some target a kinase in the MAPK pathway. Future studies should use drugs targeted to already known abnormalities (such as mutated BRAF in PTC) and other pathways such as the PI3K/AKT pathway and search for other relevant targets that may allow a more personalized treatment to be given. Further trials should also search for other treatment modalities, including combination with cytotoxic chemotherapy or sequential treatment modalities or immunotherapy (46).

Future progress will be made in three directions. First, by improving the knowledge of targets present in each individual tumor and by increasing the number of drugs directed against each of these targets, thyroid cancer patients may benefit from personalized selection of therapies. Secondly, there is an urgent need to test other drugs in thyroid cancer patients and to understand the basis of tumor response. Finally, to increase the accrual of patients, to optimize the experimental design of the protocol, to improve the characterization of tumor tissues, and to improve the tolerance of treatment, the collaborative participation of a multidisciplinary team of endocrinologists, oncologists, nuclear physicians, surgeons, pathologists, laboratory researchers, and statisticians should be strongly encouraged through national and international networks.

\section{Declaration of interest}

M Schlumberger: Amgen, Astra-Zeneca, Bayer, Exelixis, Eisai, Genzyme, Ipsen Pharma, Roche. S I Sherman: Amgen, AstraZeneca, Bayer, Exelixis, Eisai, Genzyme, Novo Nordisk, Pfizer, Roche, Veracyte.

\section{Funding}

This research did not receive any specific grant from any funding agency in the public, commercial, or not-for-profit sector.

\section{References}

1 Cooper DS, Doherty GM, Haugen BR, Kloos RT, Lee SL, Mandel SJ, Mazzaferri EL, McIver B, Pacini F, Schlumberger M, Sherman SI, Steward DL \& Tuttle RM. Revised American Thyroid Association management guidelines for patients with thyroid nodules and differentiated thyroid cancer. Thyroid 200919 1167-1214. (doi:10.1089/thy.2009.0110)

2 Baudin E \& Schlumberger M. New therapeutic approaches for metastatic thyroid carcinoma. Lancet Oncology 20078 148-156. (doi:10.1016/S1470-2045(07)70034-7)

3 Schlumberger M \& Sherman SI. Clinical trials for progressive differentiated thyroid cancer: patient selection, study design, and recent advances. Thyroid 200919 1393-1400. (doi:10.1089/thy. 2009.1603)

4 Durante C, Haddy N, Baudin E, Leboulleux S, Hartl D, Travagli JP, Caillou B, Ricard M, Lumbroso JD, De Vathaire F \& Schlumberger M. Long-term outcome of 444 patients with distant metastases from papillary and follicular thyroid carcinoma: benefits and limits of radioiodine therapy. Journal of Clinical Endocrinology and Metabolism $2006 \quad 912892-2899$. (doi:10.1210/jc.2005-2838)

5 Jonklaas J, Sarlis NJ, Litofsky D, Ain KB, Bigos ST, Brierley JD, Cooper DS, Haugen BR, Ladenson PW, Magner J, Robbins J, Ross DS, Skarulis M, Maxon HR \& Sherman SI. Outcomes of patients with differentiated thyroid carcinoma following initial therapy. Thyroid 200616 1229-1242. (doi:10.1089/thy.2006. 16.1229)

6 Biondi B, Filetti S \& Schlumberger M. Thyroid-hormone therapy and thyroid cancer: a reassessment. Nature Clinical Practice. Endocrinology and Metabolism 2005 1 32-40. (doi:10.1038/ ncpendmet0020)

7 Schwartz DL, Lobo MJ, Ang KK, Morrison WH, Rosenthal DI, Ahamad A, Evans DB, Clayman G, Sherman SI \& Garden AS. Postoperative external beam radiotherapy for differentiated thyroid cancer: outcomes and morbidity with conformal treatment. International Journal of Radiation Oncology, Biology, Physics 200974 1083-1091. (doi:10.1016/j.ijrobp.2008.09.023)

8 Eisenhauer EA, Therasse P, Bogaerts J, Schwartz LH, Sargent D, Ford R, Dancey J, Arbuck S, Gwyther S, Mooney M, Rubinstein L, Shankar L, Dodd L, Kaplan R, Lacombe D \& Verweij J. New response evaluation criteria in solid tumours: revised RECIST guideline (version 1.1). European Journal of Cancer 200945 228-247. (doi:10.1016/j.ejca.2008.10.026)

9 Therasse P, Arbuck SG, Eisenhauer EA, Wanders J, Kaplan RS, Rubinstein L, Verweij J, Van Glabbeke M, van Oosterom AT, Christian MC \& Gwyther SG. New guidelines to evaluate the response to treatment in solid tumors. European Organization for Research and Treatment of Cancer, National Cancer Institute of the United States, National Cancer Institute of Canada. Journal of the National Cancer Institute 200092 205-216. (doi:10.1093/ jnci/92.3.205)

10 Shimaoka K, Schoenfeld DA, DeWys WD, Creech RH \& DeConti R. A randomized trial of doxorubicin versus doxorubicin plus cisplatin in patients with advanced thyroid carcinoma. Cancer 198556 2155-2160. (doi:10.1002/1097-0142(19851101) 56:9<2155::AID-CNCR2820560903> 3.0.CO;2-E)

11 Williams SD, Birch R \& Einhorn LH. Phase II evaluation of doxorubicin plus cisplatin in advanced thyroid cancer: a Southeastern Cancer Study Group Trial. Cancer Treatment Reports 1986 70 405-407.

12 Sherman SI. Cytotoxic chemotherapy for differentiated thyroid carcinoma. Clinical Oncology 201022 464-468. (doi:10.1016/j. clon.2010.03.014)

13 Fagin JA. How thyroid tumors start and why it matters: kinase mutants as targets for solid cancer pharmacotherapy. Journal of Endocrinology 2004183 249-256. (doi:10.1677/joe.1.05895)

14 Kondo T, Ezzat S \& Asa SL. Pathogenetic mechanisms in thyroid follicular-cell neoplasia. Nature Reviews. Cancer 20066 292-306. (doi:10.1038/nrc1836) 
15 Volante M, Rapa I, Gandhi M, Bussolati G, Giachino D, Papotti M \& Nikiforov YE. RAS mutations are the predominant molecular alteration in poorly differentiated thyroid carcinomas and bear prognostic impact. Journal of Clinical Endocrinology and Metabolism 200994 4735-4741. (doi:10.1210/jc.2009-1233)

16 Volante M, Collini P, Nikiforov YE, Sakamoto A, Kakudo K, Katoh R, Lloyd RV, LiVolsi VA, Papotti M, Sobrinho-Simoes M, Bussolati G \& Rosai J. Poorly differentiated thyroid carcinoma: the Turin proposal for the use of uniform diagnostic criteria and an algorithmic diagnostic approach. American Journal of Surgical Pathology 200731 1256-1264. (doi:10.1097/PAS.0b013e31 $80309 \mathrm{e} 6 \mathrm{a})$

17 Ringel MD, Hayre N, Saito J, Saunier B, Schuppert F, Burch H, Bernet V, Burman KD, Kohn LD \& Saji M. Overexpression and overactivation of Akt in thyroid carcinoma. Cancer Research 2001 61 6105-6111.

18 Bruni P, Boccia A, Baldassarre G, Trapasso F, Santoro M, Chiappetta G, Fusco A \& Viglietto G. PTEN expression is reduced in a subset of sporadic thyroid carcinomas: evidence that PTENgrowth suppressing activity in thyroid cancer cells mediated by p27kip1. Oncogene 200019 3146-3155. (doi:10.1038/sj.onc. 1203633)

19 Wu G, Mambo E, Guo Z, Hu S, Huang X, Gollin SM, Trink B, Ladenson PW, Sidransky D \& Xing M. Uncommon mutation, but common amplifications, of the PIK3CA gene in thyroid tumors. Journal of Clinical Endocrinology and Metabolism 200590 4688-4693. (doi:10.1210/jc.2004-2281)

20 Santarpia L, El-Naggar AK, Cote GJ, Myers JN \& Sherman SI. PI3K/Akt and Ras/Raf-MAPK pathway mutations in anaplastic thyroid cancer. Journal of Clinical Endocrinology and Metabolism 200893 278-284. (doi:10.1210/jc.2007-1076)

21 Bunone G, Vigneri P, Mariani L, Butó S, Collini P, Pilotti S, Pierotti MA \& Bongarzone I. Expression of angiogenesis stimulators and inhibitors in human thyroid tumors and correlation with clinical pathological features. American Journal of Pathology $1999 \mathbf{1 5 5}$ 1967-1976. (doi:10.1016/ SO002-9440(10)65515-0)

22 Klein M, Vignaud JM, Hennequin V, Toussaint B, Bresler L, Plénat F, Leclère J, Duprez A \& Weryha G. Increased expression of the vascular endothelial growth factor is a pejorative prognosis marker in papillary thyroid carcinoma. Journal of Clinical Endocrinology and Metabolism 200186 656-658. (doi:10.1210/ jc.86.2.656)

23 Soh EY, Eigelberger MS, Kim KJ, Wong MG, Young DM, Clark OH \& Duh QY. Neutralizing vascular endothelial growth factor activity inhibits thyroid cancer growth in vivo. Surgery 2000 128 1059-1065; (discussion 1065-6). (doi:10.1067/msy.2000. 110430)

24 Tuttle RM, Ball DW, Byrd D, Dilawari RA, Doherty GM, Duh QY, Ehya H, Farrar WB, Haddad RI, Kandeel F, Kloos RT, Kopp P, Lamonica DM, Loree TR, Lydiatt WM, McCaffrey JC, Olson JA Jr, Parks L, Ridge JA, Shah JP, Sherman SI, Sturgeon C, Waguespack SG, Wang TN \& Wirth LJ. Thyroid carcinoma. Journal of the National Comprehensive Cancer Network $2010 \mathbf{8}$ 1228-1274.

25 Sherman SI, Wirth LJ, Droz JP, Hofmann M, Bastholt L, Martins RG, Licitra L, Eschenberg MJ, Sun YN, Juan T, Stepan DE \& Schlumberger MJ. Motesanib diphosphate in progressive differentiated thyroid cancer. New England Journal of Medicine 2008359 31-42. (doi:10.1056/NEJMoa075853)

26 Gupta-Abramson V, Troxel AB, Nellore A, Puttaswamy K, Redlinger M, Ransone K, Mandel SJ, Flaherty KT, Loevner LA, O'Dwyer PJ \& Brose MS. Phase II trial of sorafenib in advanced thyroid cancer. Journal of Clinical Oncology 200826 4714-4719. (doi:10.1200/JCO.2008.16.3279)

27 Kloos RT, Ringel MD, Knopp MV, Hall NC, King M, Stevens R, Liang J, Wakely PE Jr, Vasko VV, Saji M, Rittenberry J, Wei L, Arbogast D, Collamore M, Wright JJ, Grever M \& Shah MH. Phase II trial of sorafenib in metastatic thyroid cancer. Journal of Clinical Oncology 200927 1675-1684. (doi:10.1200/JCO.2008.18. 2717)
28 Hoftijzer H, Heemstra KA, Morreau H, Stokkel MP, Corssmit EP, Gelderblom H, Weijers K, Pereira AM, Huijberts M, Kapiteijn E, Romijn JA \& Smit JW. Beneficial effects of sorafenib on tumor progression, but not on radioiodine uptake, in patients with differentiated thyroid carcinoma. European Journal of Endocrinology 2009161 923-931. (doi:10.1530/EJE-09-0702)

29 Ahmed M, Barbachano Y, Riddell AM, Hickey J, Newbold KL, Viros A, Harrington KJ, Marais R \& Nutting CM. Analysis of the efficacy and toxicity of sorafenib in thyroid cancer - a phase II study in a UK based population. European Journal of Endocrinology 2011165 315-322. (doi:10.1530/EJE-11-0129)

30 Waguespack SG, Sherman SI, Williams MD, Clayman GL \& Herzog CE. The successful use of sorafenib to treat pediatric papillary thyroid carcinoma. Thyroid 200919 407-412. (doi:10. 1089/thy.2008.0429)

31 Leboulleux S, Bastholt L, Krause TM, De La Fouchardiere C, Tennvall Jan, Awada A, Gomez JM, Tisseron Carrasco A, Licour M \& Schlumberger Leboulleux MJ. Vandetanib in locally advanced or metastatic differentiated thyroid cancer (papillary; follicular; DTC): a randomized, double-blind phase II trial. 14th International Thyroid Congress (Paris, 2010).

32 Carr LL, Mankoff DA, Goulart BH, Eaton KD, Capell PT, Kell EM, Bauman JE \& Martins RG. Phase II study of daily sunitinib in FDGPET-positive, iodine-refractory differentiated thyroid cancer and metastatic medullary carcinoma of the thyroid with functional imaging correlation. Clinical Cancer Research $2010 \quad 16$ 5260-5268. (doi:10.1158/1078-0432.CCR-10-0994)

33 Cohen EE, Needles BM, Cullen KJ, Wong SJ, Wade JL III, Ivy SP, Villaflor VM, Seiwert TY, Nichols K \& Vokes EE. Phase 2 study of sunitinib in refractory thyroid cancer. Journal of Clinical Oncology 2008266025.

34 Cohen EE, Rosen LS, Vokes EE, Kies MS, Forastiere AA, Worden FP, Kane MA, Sherman E, Kim S, Bycott P, Tortorici M, Shalinsky DR, Liau KF \& Cohen RB. Axitinib is an active treatment for all histologic subtypes of advanced thyroid cancer: results from a phase II study. Journal of Clinical Oncology 200826 4708-4713. (doi:10.1200/JCO.2007.15.9566)

35 Bible KC, Suman VJ, Molina JR, Smallridge RC, Maples WJ, Menefee ME, Rubin J, Sideras K, Morris JC III, McIver B, Burton JK, Webster KP, Bieber C, Traynor AM, Flynn PJ, Goh BC, Tang H, Ivy SP \& Erlichman C. Efficacy of pazopanib in progressive, radioiodine-refractory, metastatic differentiated thyroid cancers: results of a phase 2 consortium study. Lancet Oncology 201011 962-972. (doi:10.1016/S1470-2045(10)70203-5)

36 Nemunaitis JJ, Senzer NN, Kurzrock R, Ng CS, Das A, Atienza RS, Zang EA, Jansen M, Ashworth S \& Hong DS. Phase I doseescalation study of E7080, a multikinase inhibitor, in patients with advanced solid tumors. Journal of Clinical Oncology 200826 14583. (doi:10.1200/JCO.2007.15.2843)

37 Sherman SI, Jarzab B, Cabanillas ME, Licitra LF, Pacini F, Martins R, Robinson B, Ball D, McCaffrey J, Shah MH, Bodenner D, Allison R, Newbold K, Elisei R, O'Brien JP \& Schlumberger M. A phase II trial of the multi-targeted kinase inhibitor, Lenvatinib (E7080), in advanced radioiodine-refractory differentiated thyroid cancer (DTC). Journal of Clinical Oncology (Meeting Abstracts) 201129 15_suppl 5503.

38 Flaherty KT, Puzanov I, Kim KB, Ribas A, McArthur GA, Sosman JA, O'Dwyer PJ, Lee RJ, Grippo JF, Nolop K \& Chapman PB. Inhibition of mutated, activated BRAF in metastatic melanoma. New England Journal of Medicine 2010363 809-819. (doi:10.1056/NEJMoa1002011)

39 Schwartz GK, Robertson S, Shen A, Wang E, Pace L, Dials H, Mendelson D, Shannon P \& Gordon M. A phase I study of XL281, a selective oral RAF kinase inhibitor, in patients (Pts) with advanced solid tumors. Journal of Clinical Oncology 200927 3513. (doi:10. 1200/JCO.2008.20.3745)

40 Lucas AS, Cohen EE, Cohen RB, Krzyzanowska MK, Chung CH, Murphy BA, Tanvetyanon T, Gilbert J, Moore DT \& Hayes DN. Phase II study and tissue correlative studies of AZD6244 (ARRY-142886) in iodine-131 refractory papillary thyroid 
carcinoma (IRPTC) and papillary thyroid carcinoma (PTC) with follicular elements. Journal of Clinical Oncology $2010 \mathbf{2 8} 5536$.

41 Leboeuf R, Baumgartner JE, Benezra M, Malaguarnera R, Solit D, Pratilas CA, Rosen N, Knauf JA \& Fagin JA. BRAFV600E mutation is associated with preferential sensitivity to mitogenactivated protein kinase kinase inhibition in thyroid cancer cell lines. Journal of Clinical Endocrinology and Metabolism 200893 2194-2201. (doi:10.1210/jc.2007-2825)

42 Abdulrahman RM, Verloop H, Hoftijzer H, Verburg E, Hovens GC, Corssmit EP, Reiners C, Gelderblom H, Pereira AM, Kapiteijn E, Romijn JA, Visser TJ \& Smit JW. Sorafenib-induced hypothyroidism is associated with increased type 3 deiodination. Journal of Clinical Endocrinology and Metabolism 201095 3758-3762. (doi:10. 1210/jc.2009-2507)

43 Robert C, Arnault JP \& Mateus C. RAF inhibition and induction of cutaneous squamous cell carcinoma. Current Opinion in Oncology 201123 177-182. (doi:10.1097/CCO.0b013e3283436e8c)

44 Poulikakos PI, Zhang C, Bollag G, Shokat KM \& Rosen N. RAF inhibitors transactivate RAF dimers and ERK signalling in cells with wild-type BRAF. Nature $2010 \mathbf{4 6 4} 427-430$. (doi:10.1038/ nature08902)
45 Tsimberidou AM, Vaklavas C, Wen S, Hong D, Wheler J, Ng C, Naing A, Tse S, Busaidy N, Markman M, Sherman SI \& Kurzrock R. Phase I clinical trials in 56 patients with thyroid cancer: the M.D. Anderson Cancer Center experience. Journal of Clinical Endocrinology and Metabolism 2009 94 4423-4432. (doi:10.1210/jc.2009-0743)

46 Hong DS, Cabanillas ME, Wheler J, Naing A, Tsimberidou AM, Ye L, Waguespack SG, Hernandez M, El Naggar AK, Bidyasar S, Wright J, Sherman SI \& Kurzrock R. Inhibition of the Ras/Raf/MEK/ERK and RET kinase pathways with the combination of the multikinase inhibitor sorafenib and the farnesyltransferase inhibitor tipifarnib in medullary and differentiated thyroid malignancies. Journal of Clinical Endocrinology and Metabolism 201196 997-1005. (doi:10.1210/jc.2010-1899)

Received 31 May 2011

Revised version received 9 August 2011

Accepted 2 September 2011 